\title{
Por que é mais difícil escutar os sons graves do que os sons médios e agudos? ${ }^{+*}$
}

Diogo Amaral de Magalhães ${ }^{1}$

Instituto Federal Catarinense - Campus São Francisco do Sul

São Francisco do Sul - SC

José de Pinho Alves Filho ${ }^{2}$

Departamento de Física - Universidade Federal de Santa Catarina

Florianópolis - SC

\section{Contextualização da resposta}

Em uma apresentação musical, se conseguirmos observar os músicos, os técnicos, os engenheiros de som e a equipe de produção, escutaremos várias expressões parecidas com: "O som está seco!”; "Falta peso!"; “Tire o brilho!”. Essas colocações quase sempre não possuem significado para o leigo, mas o possuem para os profissionais de áudio, pois seus ouvidos são treinados e eles dominam habilidades técnicas específicas. De fato, por muito tempo, a caracterização da sensação auditiva ou sonora foi inexata mesmo entre os cientistas, afinal são muitos os fatores, tais como a sensibilidade do ouvinte e a acústica local, que levam a caracterizar um som com qualidades do tipo "fraco", "forte", "alto", "seco", "pesado", etc., as quais possuem significados bastante relativos e, consequentemente, imprecisos. Outrossim, os profissionais de áudio, na maioria das vezes, utilizam termos cujos significados cotidianos são distintos dos conceitos científicos. Para os cientistas, por exemplo, um som alto é caracterizado por uma frequência alta, ao passo que para a maior parte das pessoas leigas um som alto pode significar um "volume alto".

Segundo Doria e Marinho (2006), à nossa percepção do som associamos adjetivos como fraco/forte e grave/agudo. Estas qualidades dependem de certas propriedades físicas das ondas sonoras: amplitude $(A)$ e frequência $(f)$. Por sua vez, a intensidade $I$ do som varia com o quadrado da amplitude da onda sonora. No que diz respeito à intensidade, o que é sentido por um ouvinte não coincide sempre com o que é medido por um aparelho e seu valor depende da frequência da onda sonora. Quanto à frequência, o espectro audível pelo ser humano varia entre

\footnotetext{
${ }^{+}$Why is more difficulty to hear low sounds than mid and high sounds?

* Recebido: abril de 2016. Aceito: outubro de 2016.

1 E-mail: diogo.magalhaes@saofrancisco.ifc.edu.br

2 E-mail: jopinhofilho@gmail.com
} 
$20 \mathrm{~Hz}$ e $20000 \mathrm{~Hz}$. Um som é dito grave quando sua frequência é baixa; agudo, quando alta. Quanto mais próxima uma nota musical é de $20 \mathrm{~Hz}$, mais grave ela é; e de $20000 \mathrm{~Hz}$, mais aguda. Na região intermediária, entre os graves e os agudos, definem-se os sons ditos médios. Sons acima de $0 \mathrm{~Hz}$ e menores do que $20 \mathrm{~Hz}$ são ditos infrassons, enquanto que aqueles acima de 20000 Hz são denominados ultrassons. Dessa forma, por exemplo, "pesar o som", no sentido popular, significa aumentar a intensidade do som das frequências mais graves, enquanto que "tirar o brilho do som" significa diminuir a intensidade do som das frequências mais agudas.

Dentre os fatores que influenciam na interpretação da sensação auditiva do homem estão a distância do ouvinte em relação à fonte sonora, a intensidade do som e a estrutura fisiológica dos ouvintes. Por fim, a questão proposta envolve fundamentalmente os conceitos de audibilidade, que é uma ideia subjetiva, e de nível de audibilidade, que a quantifica.

\section{O caminho para a resposta}

Com o intuito de se estabelecer um padrão conceitual para evitar ambiguidades na compreensão dos conceitos relacionados à audibilidade do som, Fletcher e Munson (1933) ${ }^{3}$ apresentaram a definição elaborada por um comitê científico da época para a audibilidade e seus processos de medida e cálculos. Para os autores, a audibilidade é um conceito fisiológico utilizado para descrever a magnitude da sensação auditiva, cujas comparações são feitas em relação a uma frequência de $1000 \mathrm{~Hz}$. Dois dos motivos que justificam esta padronização são: i) a frequência de $1000 \mathrm{~Hz}$ está na faixa central do espectro audível humano; ii) muitas vezes a frequência de $1000 \mathrm{~Hz}$ é utilizada na distinção entre os sons graves e agudos.

Além dos sons audíveis, divididos em sons graves, médios e agudos, podemos caracterizar uma faixa de audibilidade e outra faixa de dor. O limiar de audibilidade humana trata-se da intensidade sonora mínima $I_{0}$ que um ouvido é capaz de escutar, abaixo da qual o som não é audível; o limiar de dor corresponde à intensidade sonora máxima $I_{m}$ que nosso ouvido pode suportar, a partir da qual temos a sensação de dor ou desconforto (NUSSENSVEIG, 2002). Os limiares de audibilidade e dor dependem da frequência do som: para $f=1000 \mathrm{~Hz}$, por exemplo, $I_{0}=10^{-12} \mathrm{Wm}^{-2}$ e $I_{m}=1 \mathrm{Wm}^{-2}$. Notemos que, para respondermos à questão proposta, precisaremos analisar qual é o limiar de audibilidade para cada frequência.

Antes, observemos que a diferença entre $I_{0}$ e $I_{m}$ são de muitas ordens de grandeza, o que dificulta seu uso diário. Na prática, ao invés da intensidade, trabalha-se com o nível de intensidade sonora $\beta$, o qual é expresso em decibéis $(\mathrm{dB})$. A expressão que relaciona a intensidade sonora com o nível de intensidade sonora é $\beta=10 \log _{10}\left(I / I_{0}\right)$ (NUSSENSVEIG, 2002). Agora já temos ferramentas para compreendermos suficientemente bem (pedagogicamente falando) a quantificação da audibilidade do som, o que é feito através do conceito de nível de audibilidade.

\footnotetext{
${ }^{3} \mathrm{O}$ artigo de Fletcher e Munson (1933) é historicamente um trabalho clássico para o desenvolvimento da Acústica e, consequentemente, de diversos ramos da Engenharia.
} 


\section{Sensação auditiva e nível de audibilidade}

O nível de audibilidade de qualquer som é obtido pelo ajuste do nível de intensidade do som de referência até que ele soe com o mesmo volume segundo o julgamento de um típico ouvinte, isto é, uma pessoa que tenha audição normal para tais testes, tal que ela apresente os resultados coerentes com a média obtida a partir de um número maior de tais ouvintes (FLETCHER; MUNSON, 1933). A caracterização da intensidade de referência $I_{0}$ refere-se ao limiar de audibilidade médio destes ouvintes.

A unidade de nível de audibilidade é denominada fon. Por definição, seu valor unitário é numericamente igual ao nível de intensidade sonora, em $\mathrm{dB}$, da frequência de referência de $1000 \mathrm{~Hz}$, para um grupo de típicos ouvintes. No trabalho de Fletcher e Munson (1933), a determinação dos níveis de audibilidade, por comparação com um tom de referência, foi realizada através dos sons ditos estáveis que, grosso modo, podemos considerar aqueles que são distintos dos ruídos. Com os resultados obtidos, os autores construíram as chamadas curvas de igual audibilidade, as quais estão representadas na Fig. $1^{4}$.

Observamos que as frequências compreendidas entre $800 \mathrm{~Hz}$ e $6000 \mathrm{~Hz}$, médias e agudas, são mais facilmente audíveis pelos seres humanos do que as baixas e as muito altas. Ademais, vemos que a curva de audibilidade de 0 fon, que, por sua vez, corresponde ao nível de intensidade de $0 \mathrm{~dB}$ para $f=1000 \mathrm{~Hz}$, apresenta frequências entre $1000 \mathrm{~Hz}$ e $6000 \mathrm{~Hz}$ que são audíveis em níveis de intensidade negativas, entre $-10 \mathrm{~dB}$ e $0 \mathrm{~dB}$. Notemos que os valores negativos (de logaritmos, na base 10) não representam problemas físicos, visto que esses valores correspondem a intensidades necessariamente positivas. Em outras palavras, o argumento do logaritmo sempre será bem definido.

Ao analisar a curva de 0 fon, concluímos que para percebermos os sons graves, entre $20 \mathrm{~Hz}$ e $800 \mathrm{~Hz}$, e também os mais agudos, a partir de $6000 \mathrm{~Hz}$, eles devem ter um nível de intensidade relativamente maior do que os sons entre $800 \mathrm{~Hz}$ e $6000 \mathrm{~Hz}$. Por exemplo, para que um som a uma frequência de $50 \mathrm{~Hz}$ seja perceptível ao ouvido humano típico, é necessário que ele tenha um nível de intensidade ligeiramente superior a $50 \mathrm{~dB}$, cujo valor corresponde a $0 \mathrm{~dB}$ para a curva de 0 fon. Ou seja, para um típico ouvinte, um som de $50 \mathrm{~Hz}$ a aproximadamente $50 \mathrm{~dB}$ soa igualmente perceptível a um som de $1000 \mathrm{~Hz}$ a $0 \mathrm{~dB}$, a 0 fon. Isto corresponde a um som de intensidade quase 17 vezes maior, já que a intensidade sonora dobra a cada $3 \mathrm{~dB}$.

\footnotetext{
${ }^{4}$ Cabe ressaltar que o gráfico das curvas de igual audibilidade, proposto inicialmente por Fletcher e Munson (1933), foi aprimorado ao longo dos anos. Porém, seu significado não perdeu sentido com o passar do tempo, tal que sua forma qualitativa não foi alterada. $\mathrm{O}$ objetivo aqui é ressaltar a importância histórica de um trabalho para um dado segmento de pesquisa e desenvolvimento.
} 


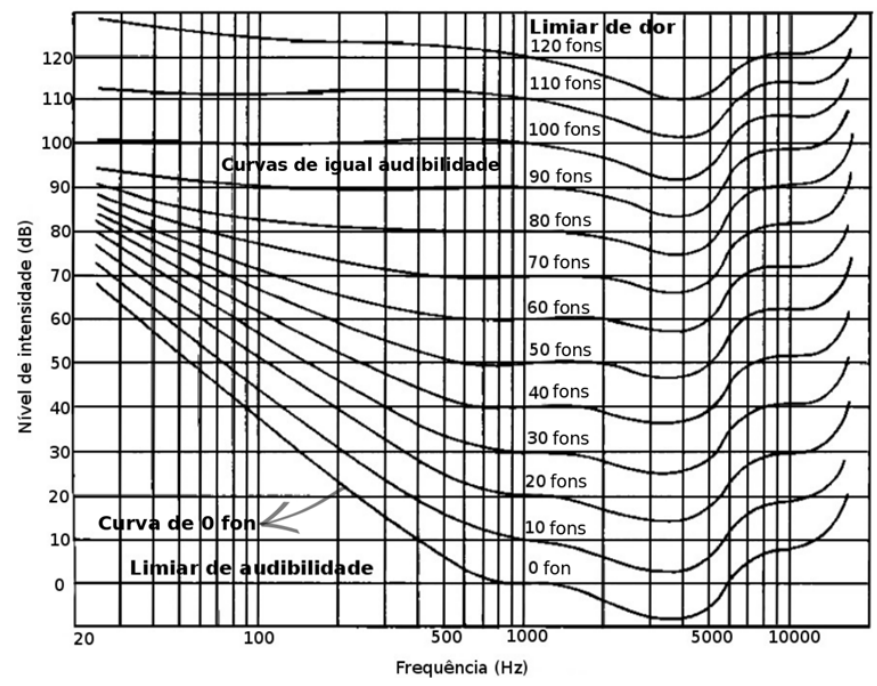

Fig. 1 - Gráfico em escala logarítmica das curvas de igual audibilidade, adaptado de Fletcher e Munson (1933). A região no canto inferior esquerdo, abaixo da curva de 0 fon, retrata a pouca sensibilidade humana para as frequências mais graves (20 Hz-800 Hz), para as quais os níveis de intensidade mínimos necessários para percepção estão bastante acima dos níveis das frequências médias e agudas (entre $1000 \mathrm{~Hz}$ e $6000 \mathrm{~Hz}$ ).

Até aqui, foram analisados apenas os fatos sobre a percepção dos sons pelo homem, mas ainda não explicamos por que nossa audição funciona assim, ou seja, por que temos mais facilidade na percepção dos sons médios e agudos, tipicamente entre $1000 \mathrm{~Hz}$ e $6000 \mathrm{~Hz}$, ou dificuldade na percepção dos sons graves e também dos mais agudos (acima de $6000 \mathrm{~Hz}$ ).

\section{A explicação biofísica}

O ouvido humano é constituído de três partes: os ouvidos externo, médio e interno. Essencialmente, eles são compostos, respectivamente, por: orelha e canal auditivo; tímpano, martelo, bigorna e estribo; e cóclea (CAMERON; SKOFRONICK; GRANT, 1999; DURÁN, 2003; DORIA; MARINHO, 2006). A Fig. 2 representa esquematicamente a estrutura anatômica do ouvido humano.

Para os seres humanos, a principal função da orelha (ou pavilhão auditivo) é direcionar o som para o canal auditivo, podendo ser até dispensável para fins auditivos (CAMERON; SKOFRONICK; GRANT, 1999; DURÁN, 2003). Entretanto, para os animais, a orelha possui a propriedade de captar a energia sonora e direcioná-la potencialmente para o canal auditivo (CAMERON; SKOFRONICK; GRANT, 1999), amplificando o som em certas faixas de frequência (DURÁN, 2003). Os gatos, por exemplo, com suas orelhas pontiagudas, são capazes de escutar sons de $60 \mathrm{~Hz}$ até a região do ultrassom, a saber, $60000 \mathrm{~Hz}$. 


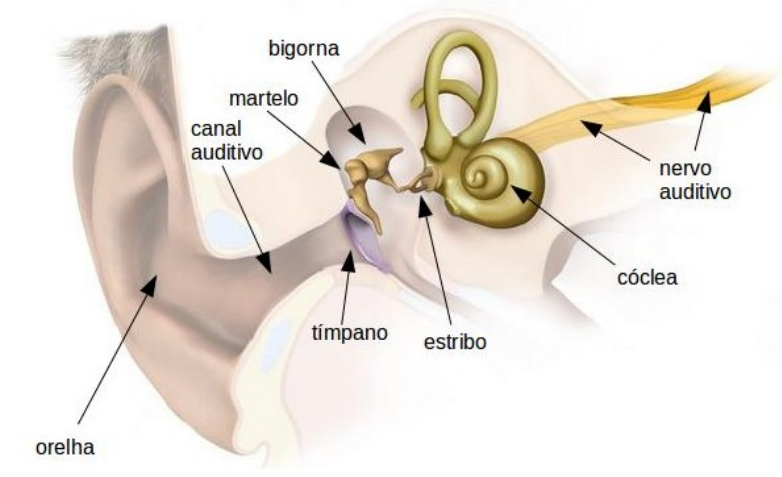

Fig. 2 - Figura esquemática do ouvido humano. No ouvido, a informação sonora atravessa os meios gasoso, líquido e sólido até ser transformada em informação elétrica que é enviada ao cérebro.

No canal auditivo, a informação sonora propaga-se pelo ar até que chegue ao tímpano ou membrana timpânica, uma membrana que passa a vibrar como a pele de um tambor na mesma frequência da onda sonora recebida. O canal auditivo pode ser representado por um tubo de órgão com uma extremidade fechada (CAMERON; SKOFRONICK; GRANT, 1999), como mostra a Fig. 3.

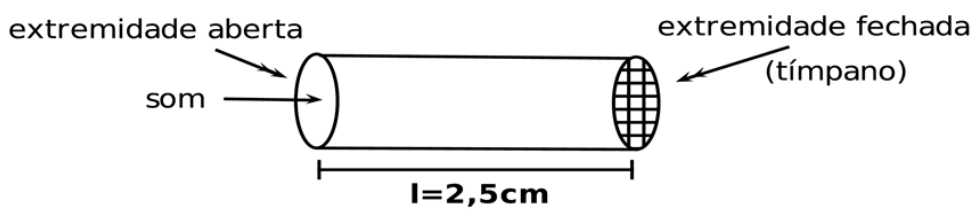

Fig. 3 - Representação do canal auditivo: um tubo sonoro com uma das extremidades fechadas.

As frequências naturais $f_{n}$ de um tubo fechado em uma das extremidades são dadas pela expressão $f_{n}=(2 n+1)(v / 4 l)$, onde $n=0,1,2, \ldots$ e v é a velocidade do som no meio (NUSSENSVEIG, 2002). O comprimento $l$ do canal auditivo, em média, é igual a $2,5 \mathrm{~cm}$ (CAMERON; SKOFRONICK; GRANT, 1999; DURÁN, 2003). Nas condições normais de temperatura e pressão, $v=332 \mathrm{~m} / \mathrm{s}$. Portanto, a primeira frequência natural $(n=0)$ do canal auditivo é $3320 \mathrm{~Hz}$. Este valor corresponde às observações de Fletcher e Munson (1933), cujo valor mínimo da curva de 0 fon encontra-se entre $3000 \mathrm{~Hz}$ e $4000 \mathrm{~Hz}$. Dito de outra maneira, frequências próximas a $3320 \mathrm{~Hz}$ são mais facilmente perceptíveis pelos seres humanos porque o canal auditivo potencializa a percepção dessa região do espectro sonoro. Este cálculo relativamente simples explica o motivo do ser humano ter mais facilidade em perceber os sons médios e agudos, entre $1000 \mathrm{~Hz}$ e $6000 \mathrm{~Hz}$, do que os sons graves. Na sequência, abordamos outros aspectos complementares à compreensão da audibilidade do som. 
A membrana timpânica é conectada ao martelo, que por sua vez é ligado à bigorna $\mathrm{e}$ esta com o estribo. Esta estrutura comunicada de ossículos oscila na mesma frequência da informação sonora original, além de funcionar como um amplificador da vibração mecânica (DORIA; MARINHO, 2006). É possível mostrar que a pressão que iniciará o percurso do ouvido interno é 20 vezes maior do que a pressão imprimida pelo canal auditivo sobre o tímpano. Esta amplificação é importante porque no ouvido interno a cóclea está submersa em um líquido, onde será necessária uma pressão maior do que no ar.

A cóclea tem fundamental importância no processo de audição humana. Ela é separada em compartimentos e tem a forma de um caracol, cujo esboço da estrutura "desenrolada" está representado na Fig. 4. De acordo com Reichenbach e Hudspeth (2014) ${ }^{5}$, a cóclea funciona como um analisador espectral em tempo real, altamente não linear e adaptável. Sua constituição contém a membrana basilar, a qual se comporta como um analisador de frequências sonoras, tal que cada região responde a uma determinada frequência do som e sua amplitude de movimento depende da intensidade dos sons recebidos, segundo as ondulações do líquido (DORIA; MARINHO, 2006). Sua extensão revela uma estrutura de tubos ou canais, denominados escalas vestibular, média e timpânica. A membrana basilar situa-se na escala média.

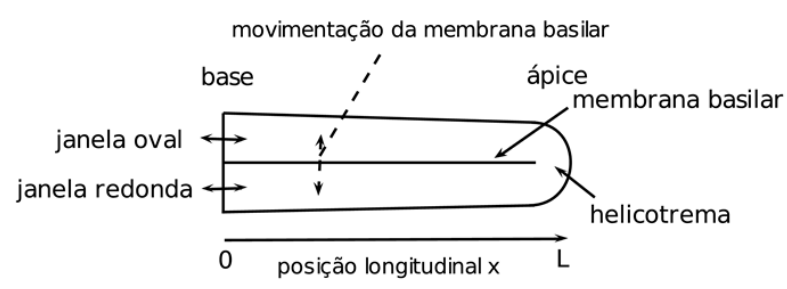

Fig. 4 - Seção longitudinal da cóclea desenrolada que ilustra sua estrutura interna. A figura é adaptada da original, disponível em Reichenbach e Hudspeth (2014).

Segundo Reichenbach e Hudspeth (2014), as propriedades físico-químicas da membrana basilar variam significativamente ao longo de sua extensão. Sua rigidez $k$ decai exponencialmente com a distância longitudinal a partir de sua base enquanto sua massa $m$ cresce exponencialmente até seu ápice. Isso explica por que nossos ouvidos funcionam de forma logarítmica. Pensando simplificadamente em um modelo massa mola, tem-se que cada região da membrana basilar responde a determinada frequência que é proporcional a $(\mathrm{k} / \mathrm{m})^{1 / 2}$. Portanto, na base, sua sensibilidade é maior para os sons mais agudos, pois a membrana basilar, sendo mais rígida e menos massiva, ressona melhor com frequências mais altas; já no topo, a membrana basilar, sendo menos rígida e mais massiva, é mais sensível aos sons graves. Esta análise pode ser simulada fixando-se uma das extremidades de uma régua sobre uma mesa e

\footnotetext{
${ }^{5} \mathrm{O}$ artigo de Reichenbach e Hudspeth (2014) é uma referência técnica, ampla e profunda sobre a física da audição, cujos detalhamentos fogem do escopo da nossa proposta.
} 
colocando a outra ponta da régua fora da mesa, fazendo-a vibrar como um trampolim. Nesta situação, observa-se sons mais agudos para "trampolins" de menor comprimento e sons mais graves para "trampolins" mais compridos.

Dessa forma, um som com uma frequência bem definida percorre toda extensão da membrana basilar até que a estimula em uma região específica, quando ocorre a ressonância. Quanto menor for a diferença entre a frequência do som e a frequência da natural da membrana basilar, maior será sua amplitude de oscilação. Ao longo dela, situadas no órgão de Corti, existem as células ciliadas, as componentes mecanicamente sensíveis que transformam a informação mecânica em elétrica, que é conduzida pelos nervos auditivos até que seja finalmente interpretada no cérebro (DURÁN, 2003).

\section{Comentários finais}

O fato dos seres humanos serem menos sensíveis a sons graves se deve ao canal auditivo, que privilegia a percepção de frequências entre $3000 \mathrm{~Hz}$ e $4000 \mathrm{~Hz}$, como já discutimos anteriormente.

Outro ponto interessante que poderia ser abordado acerca da audibilidade do som é a distinção dos sons graves. Por que os sons graves "soam mais parecidos uns com os outros" do que os sons médios?

Um aspecto prático da audibilidade sonora se dá durante shows musicais ao vivo. Visando o equilíbrio da sensação auditiva de todos os sons produzidos pelos instrumentos da banda, os técnicos de som utilizam vários equipamentos. Um deles é o equalizador de som, cuja função é atenuar ou aumentar a intensidade de faixas de frequência específicas. Assim, nossa limitação na percepção dos sons graves e dos mais agudos pode ser corrigida com este aparato tecnológico. Mas ele não deve ser utilizado sem analisar outros fatores, tais como a acústica do local da apresentação musical.

Uma última questão interessante que poderia ser explorada em sala de aula envolve as amplitudes de deslocamento das moléculas de ar que transportam a energia sonora até a captação pelo tímpano, que são da ordem de $10^{-11} \mathrm{~m}$ até $10^{-5} \mathrm{~m}$. Ou seja, nosso ouvido, mais especificamente a membrana timpânica, é capaz de captar vibrações de ordem de grandeza da centésima parte de um milímetro até a escala atômica!

\section{Referências bibliográficas}

CAMERON, J. R.; SKOFRONICK, J. G.; GRANT, R. M. Physics of the body. Madison: Medical Physics Publishing, 1999.

DORIA, M. M.; MARINHO, F. C. Ondas e Bits. São Paulo: Editora Livraria da Física, 2006. 
DURÁN, J. E. R. Biofísica: Fundamentos e Aplicações. São Paulo: Pearson Prentice Hall, 2003.

FLETCHER, H.; MUNSON, W. A. Loudness, Its Definition, Measurement and Calculation. Journal of the Acoustical Society of America, v. 5, n. 2, p. 82-108, 1933.

NUSSENSVEIG, M. Curso de Física básica. São Paulo: Edgar Blücher, 2002. v. 2.

REICHENBACH, T.; HUDSPETH, A. J. The physics of hearing: fluid mechanics and the active process of the inner ear. Reports on Progress in Physics, v. 77, n. 7, p. 1-45, 2014. 